\title{
First report of Leptospira infections in red deer, roe deer, and fallow deer in Poland
}

\author{
Jacek Żmudzki ${ }^{1}$, Artur Jabłoński ${ }^{1}$, Zbigniew Arent ${ }^{3}$, \\ Sylwia Zębek ${ }^{1}$, Agnieszka Nowak ${ }^{1}$, Agnieszka Stolarek ${ }^{2}$, \\ Marta Parzeniecka-Jaworska ${ }^{4}$ \\ ${ }^{1}$ Department of Swine Diseases, ${ }^{2}$ Department of Epidemiology and Risk Assessment, \\ National Veterinary Research Institute, 24-100 Pulawy, Poland \\ ${ }^{3}$ University Centre of Veterinary Medicine, University of Agriculture in Krakow, \\ Jagiellonian University, 30-059, Krakow, Poland \\ ${ }^{4}$ Division of Laboratory and Clinical Diagnostics, \\ Department of Pathology and Veterinary Diagnostics, Faculty of Veterinary Medicine, \\ University of Life Sciences, 02-776, Warsaw, Poland \\ jaca@piwet.pulawy.pl
}

Received: February 28, 2016 Accepted: July 20, 2016

\begin{abstract}
Introduction: Recently in Europe an increase in the population of red deer (Cervus elaphus), roe deer (Capreolus capreolus), and fallow deer (Dama dama) has been observed. Research on the prevalence of Leptospira infections in Polish cervids has been performed for the first time. Material and Methods: During 2014/2015 hunting season, 147 blood samples from red deer, roe deer, and fallow deer were collected. The animals originated from different geographical regions across Poland. Serum samples were tested by microscopic agglutination test (MAT) for the presence of specific antibodies to the following Leptospira serovars: Icterohaemorrhagiae, Grippotyphosa, Sejroe, Tarassovi, Pomona, Canicola, Bratislava, Hardjo, Ballum, Zanoni, Hebdomadis, and Poi. Results: Serum antibody titres specific to Grippotyphosa, Pomona, and Zanoni serovars were found; none of the sera were positive for any of the other serovars. Out of 147 serum samples only 7 were positive, which gave an overall prevalence of $4.8 \%$ in the tested animal population. Conclusion: The low Leptospira antibody titres along with the low number of positive serum samples in deer indicate that these animals may not act as significant reservoirs of Leptospira for either humans or animals in Poland.
\end{abstract}

Keywords: cervids, Leptospira, antibodies, epidemiology, zoonosis.

\section{Introduction}

Wildlife may play a role in the maintenance and spread of leptospirosis to domestic animals and humans by acting as reservoirs of Leptospira infection (8). Among many free-living game species in the natural environment, deer are the most common and important animals, and red deer, roe deer, and follow deer are known representatives of the Cervidae family in Polish forests. In the last decade, in Poland, the population of red deer has nearly doubled from 100000 animals in 2003-2004 to over 180000 individuals in the last two years. A similar situation has occurred in roe deer and fallow deer, where increase in their population from 600000 to 800000 (2003-2004) and from 7500 to 20000 (2013-2014) respectively was observed (21). The samples for this study were collected from animals in a woodlanddominated area, which derives considerable economic benefits from hunting. In Poland, during 2014-2015 hunting season, out of a population estimated at 213500 animals, 83000 red deer were shot. In the case of roe deer and fallow deer the numbers were 195000 (out of 867000 ) and 8600 (out of 27542 ) respectively (5). 
Due to increasing populations of these animals, transmission of leptospirosis to people and other species is highly possible. The objective of our study was to determine the prevalence of Leptospira antibodies in deer population in 12 Polish provinces. To the best of our knowledge, so far no surveys on the epidemiological situation of leptospirosis in deer have been performed in Poland.

\section{Material and Methods}

A total of 147 blood samples were collected during 2014/2015 hunting season in Poland. The red deer $(n=103)$, roe deer $(n=37)$, and fallow deer $(\mathrm{n}=7)$ sera were obtained from 12 of the 16 provinces (Table 1). Blood was collected from the deer during evisceration; therefore no ethical committee approval was required. Samples were collected mainly from blood vessels in the neck area and occasionally from body cavities. Additionally, peritoneal fluid containing blood was collected. The samples were centrifuged at $5000 \mathrm{~g}$ for $20 \mathrm{~min}$ to remove the cellular components of blood, tissue debris, and bacterial contaminants. The obtained supernatant was used for serological testing. Animals, which were shot in the abdomen, were not included in the study. All samples were frozen at $-18^{\circ} \mathrm{C}$ until analysis.

Serum samples were tested by microscopic agglutination test (MAT) $(17,23)$ with the following 12 Leptospira serovars: Icterohaemorrhagiae (strain RGA, representing serogroup Icterohaemorrhagiae), Grippotyphosa (strain Moskva V, serogroup Grippotyphosa), Sejroe (strain M84, serogroup Sejroe), Tarassovi (strain Perepelicyn, serogroup Tarassovi), Pomona (strain Pomona, serogroup Pomona), Canicola (strain Hond Utrecht IV, serogroup Canicola), Bratislava (strain S/820834, serogroup Australis), Hardjo (strain Hardjoprajitno, serogroup Sejroe), Ballum (strain MUS127, serogroup Ballum), Zanoni (strain Zanoni, serogroup Pyrogenes), Hebdomadis (strain Hebdomadis, serogroup Hebdomadis), and Poi (strain Poi, serogroup Javanica). The reference strains were provided by the Veterinary Sciences Division, AFBI, OIE Leptospira Reference Laboratory, Belfast, and by the Royal Tropical Institute-WHO/FAO Collaborating
Centre for Reference and Research on Leptospirosis, Amsterdam. Each antigen was grown in a $10 \mathrm{~mL}$ volume of Ellinghausen-McCullough-Johnson-Harris (EMJH) medium at $28^{\circ} \mathrm{C}$. After 6-10 days' growth (depending on the antigen), the antigens were adjusted to $1-2 \times 10^{8}$ cells $/ \mathrm{mL}$ by cell count using a Helber counting chamber. The sera were initially scanned for antibodies to the antigens at a final dilution of 1:100. When there was evidence of agglutination, the relevant sera were end-point tested using doubling dilutions starting at a final serum dilution of 1:100 to 1:25 600. The serological titre for each serovar was considered to be the highest dilution at which there was sufficient antibody present to agglutinate $50 \%$ or more of the antigen.

For statistical and spatial analysis (maps), the STATISTICA (data analysis software system), version 10 (StatSoft, Inc.) and ArcGIS 10.3.1 for Desktop Standard (ESRI, Inc.) were used. Exact confidence intervals based on $\beta$-distribution were calculated.

\section{Results}

From a total of 147 serum samples, antibodies against particular Leptospira serovars were found in only seven samples (one serum sample reacted with two serovars, which produced eight positive reactions), resulting in overall prevalence at the level of $4.8 \%$ (0.95 CI: $1.9-9.6 \%$ ) from 12 Polish provinces (Table 1). None of the sera had titres to serovars Icterohaemorrhagiae, Sejroe, Canicola, Bratislava, Hardjo, Ballum, Hebdomadis, or Poi.

Seropositive samples from red deer, roe deer, and fallow deer were found in the following provinces: Dolnośląskie - 20.0\% (0.95 CI: 2.5\%-55.6\%) (Zanoni with titre of 100 and Pomona with titre of 400); Podkarpackie - 13.3\% (0.95 CI: $1.7 \%-40.5 \%$ ) (one serum sample had antibodies against serovars Pomona and Grippotyphosa both with the same titre of 100); Zachodniopomorskie - 18.2\% (0.95 CI: $2.3 \%-51.8 \%$ ) (Zanoni with titre of 100 and Grippotyphosa with titre of 200); and Opolskie - 2.9\% (0.95 CI: 0.1\%-15.3\%) (Grippotyphosa with titre of 100) (Fig. 1) while the other eight provinces were negative to the tested Leptospira sp. serovars.

Table 1. Distribution of Leptospira interrogans antibody titres for seven positive red deer, roe deer, and fallow deer hunted during $2014-2015$ season in Poland

\begin{tabular}{|c|c|c|c|c|}
\hline \multirow{3}{*}{$\begin{array}{l}\text { Serovar } \\
\text { Pomona }\end{array}$} & \multicolumn{3}{|c|}{ Number of antibody-positive samples (\%) } & \multirow[b]{2}{*}{ Total } \\
\hline & $1: 100$ & $1: 200$ & $1: 400$ & \\
\hline & $2 \quad(1.4 \%)$ & 0 & $1 \quad(0.7 \%)$ & $3(2.0 \%)$ \\
\hline Grippotyphosa & $2 \quad(1.4 \%)$ & $1(0.7 \%)$ & 0 & $3(2.0 \%)$ \\
\hline Zanoni & $2 \quad(1.4 \%)$ & 0 & 0 & $2(1.4 \%)$ \\
\hline
\end{tabular}




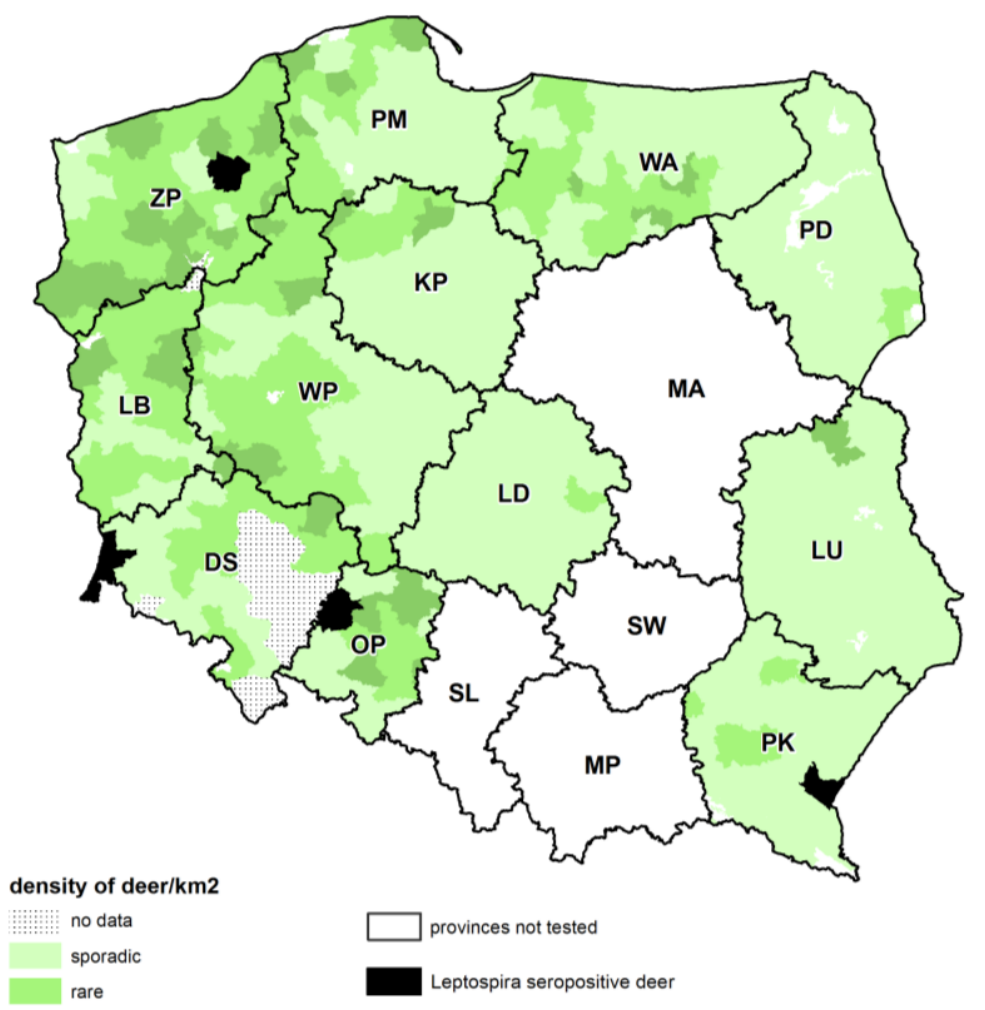

Fig. 1. Geographical distribution of red deer, roe deer, and fallow deer in Poland in 2015, as well as Leptospira interrogans serovars Grippotyphosa, Pomona, and Zanoni antibody-positive deer sampled from 2014 to 2015. DS - Dolnośląskie; KP Kujawsko-Pomorskie; LB - Lubuskie; LD - Łódzkie; LU - Lubelskie; MA Mazowieckie; MP - Małopolskie; OP - Opolskie; PD - Podlaskie; PK - Podkarpackie; PM - Pomorskie; SL - Śląskie; SW - Świętokrzyskie; WA - Warmińsko-Mazurskie; WP - Wielkopolskie; ZP - Zachodniopomorskie

\section{Discussion}

This study investigated the prevalence of pathogenic Leptospira sp. serovars in samples collected from red, roe, and fallow deer in different geographical areas across Poland. The animals tested showed a seroreactivity rate of $4.8 \%$ at a titre of 100 or higher. The antibody titres in the present study were low and never exceeded 400; in other studies the titres reached 3200 (1).

The epidemiological picture of these infections in several European countries is similar to our results. A comparable level of exposure was demonstrated in Croatia (6.0\%) (20) and Italy (6.3\%) (1). In Spain, Lavín et al. (15) reported an overall Leptospira sp. seroprevalence of $12.9 \%$ in fallow deer, but did not specify the most prevalent serovars, while Espí et al. (9) recorded a prevalence lower by half, with Pomona as the predominant serovar among fallow deer (5.8\%), and serovar Muenchen (serogroup Australis) being the most frequent among Iberian red deer $(2.6 \%)$.

The most dominant serovars in Polish deer were Grippotyphosa and Pomona, which is consistent with other authors $(1,9)$. The exposure to these serovars is not surprising, considering the previous studies in
Poland where Grippotyphosa and Pomona where also very common between horses, pigs (mainly serovar Pomona), and wild boars $(3,22,24)$. Taking into account the low seroprevalence rate and exposure to different serovars it is likely that these infections are rather accidental because red, roe, and fallow deer all act as maintenance hosts for them.

In Czech Republic, in the serological survey of 4634 specimens of wild mammals, $12 \%$ were positive and from these $99 \%$ had antibodies to Grippotyphosa (21). Grippotyphosa was also reported as one of the most common causes of clinical leptospirosis in humans and dogs in Germany $(6,11,12)$. Serovar Grippotyphosa is maintained by a number of small rodents in Europe: the common vole (Microtus arvalis) (4, 10, 14), muskrat (Ondatra zibethicus) (7), common hamster (Cricetus cricetus) (16), wood mouse (Apodemus sylvaticus), and yellow-necked mouse (Apodemus flavicollis) $(19,21)$. All of these occur in Poland (26) and it is likely that some of them constitute a natural reservoir of this serovar for domestic and wild animals.

Leptospira belonging to serogroup Pomona is one of the most commonly identified in wild and domestic animals all over the world. It is a very heterogenic 
group of organisms. Some of them, particularly serovars belonging to L. interrogans species such as serovar Pomona, have been shown to be significant domestic animal pathogens, maintained by pigs (8). However, serogroup Pomona strains clustered in L. kirschneri species, like serovars Mozdok and Altodouro, are maintained by small rodents, although they may also occasionally cause disease in domestic animals $(2,13,18)$. Taking into account all the above data and the fact that bacteriological studies are limited in Poland, definitive comments on the epidemiology of serogroup Pomona infections in animals will require further investigations, as this can only be assessed by renal culture, which was not part of this study.

In conclusion, the presented data confirm that there is a low number of Leptospira infections among deer in various European countries, including Poland. The results also indicate that deer is probably not an important vector in the spread of leptospirosis in humans, e.g. people working in the forest environment. Due to the low number of tested samples further inquiry into the prevalence of the infection among red, roe, and fallow deer is needed.

Conflict of Interests Statement: The authors declare that there is no conflict of interests regarding the publication of this article.

Financial Disclosure Statement: This study was supported by the Polish National Science Centre (grant number DEC-2013/09/B/NZ7/02563).

Animal Rights Statement: None required.

Acknowledgements: We are grateful to the hunters of all 12 provinces; without their help this investigation would not have been possible. The authors would like to warmly thank Łukasz Bocian for statistical analysis. Special thanks to Professor Zygmunt Giżejewski for his valuable comments and correction of the manuscript.

\section{References}

1. Andreoli E., Radaelli E., Bertoletti I., Bianchi A., Scanziani E., Tagliabue S., Mattiello S.: Leptospira spp. infection in wild ruminants: a survey in Central Italian Alps. Vet Ital 2014, 50, 285-291.

2. Arent Z.J., Andrews S., Adamama-Moraitou K., Gilmore C., Pardali D., Ellis W.A.: Emergence of novel Leptospira serovars: a need for adjusting vaccination policies for dogs? Epidemiol Infect 2013, 141, 1148-1153.

3. Arent Z.J., Kedzierska-Mieszkowska S.: Seroprevalence study of leptospirosis in horses in northern Poland. Vet Rec 2013, $172,269$.

4. Boricic B., Kovacic H., Sebek Z., Aleraj B., Tvrtkovic N.: Small terrestrial mammals as reservoirs of leptospires in the Sava Valley (Croatia). Folia Parasitol 1982, 29, 177-182.
5. Central Statistical Office, 2015. Environment. URL: http://www.stat.gov.pl

6. Desai D.S., Van Treeck U., Lierz M., Espelage W., Zota L., Sarbu A., Czerwinski M., Sadowska-Todys M., Advicova M., Reetz J., Luge E., Guerra B., Nockler K., Jansen A.: Resurgence of field fever in a Temperate country: an epidemic of leptospirosis among seasonal strawberry harvesters in Germany in 2007. Clin Infect Dis 2009, 48, 691-697.

7. Desmecht M., Smeets L.: The muskrat as one of the principal sources of leptospires for cattle? Annal Med Vet 1989, 133, 413-419.

8. Ellis W.A.: Leptospirosis. In: Diseases of swine. Edited by Zimmerman J.J., Karriker L.A., Ramirez A., Schwartz K.J., Stevenson G.W., John Wiley \& Sons; Iowa, 2012. pp. 770-778.

9. Espí A., Prieto J.M., Alzaga V.: Leptospiral antibodies in Iberian red deer (Cervus elaphus hispanicus), fallow deer (Dama dama) and European wild boar (Sus scrofa) in Asturias, Northern Spain. Vet J 2010, 183, 226-227.

10. Fennestad K.L., Borg-Petersesn C.: Leptospirosis in Danish wild mammals. J Wildl Dis 1972, 8, 343-351.

11. Geisen V., Stengel C., Brem S., Muller W., Greene C., Hartmann K.: Canine leptospirosis infections - clinical signs and outcome with different suspected Leptospira serogroups (42 cases). J Small Anim Pract 2007, 48, 324-328.

12. Jansen A., Schöneberg I., Frank C., Alpers K., Scneider T., Stark K.: Leptospirosis in Germany, 1962-2003. Emerg Infect Dis 2005, 11, 1048-1054.

13. Kocik T.: Isolation of Leptospira interrogans serovar mozdok from an outbreak of leptospirosis in pigs. Med Weter 1989, 45, 409-411.

14. Kuiken T., Van Dijk J.E., Terpstra W.J., Bokhout B.A.: The role of the common vole (Microtus arvalis) in the epidemiology of bovine infection with Leptospira interrogans serovar hardjo. Vet Microbiol 1991, 28, 353-361.

15. Lavín S., Ruiz-Bascará M., Marco I., Viñas L.: Ecopatología del gamo (Dama dama) en el Principado de Asturias. Vet Castilla León 1998, 9, 15-18.

16. Mochmann H.: The role of the field hamster (Cricetus cricetus) as a source of infection of the swamp-field fever. Z Hyg Infektionskr 1957, 143, 327-333.

17. Office International des Epizooties, Leptospirosis, 2014. www.oie.int/fileadmin/Home/eng/Health_standards/tahm/2.01.0 9_LEPTO.pdf.

18. Paiva-Cardoso M.N., Arent Z., Gilmore C., Hartskeerl R.: Altodouro, a new Leptospira serovar of the Pomona serogroup isolated from rodents in northern Portugal. Infect Genet Evol 2013, 13, 211-217.

19. Sebek Z., Vlcek M., Sterba J.: Small mammals as reservoir and transmitters of leptospires in livestock-breeding farms and their surroundings. Folia Parasitol 1983, 30, 363-371.

20. Slavica A., Cvetnić Ž., Milas Z., Janicki Z., Turek N., Konjević D., Severin K., Tončić J., Lipej Z.: Incidence of leptospiral antibodies in different game species over a 10-year period (1996-2005) in Croatia. Eur J Wildl Res 2008, 54, 305-311.

21. Treml F., Nesnalova E.: Serologic screening for the occurrence of Leptospira antibodies in small wild mammals. Veterinarni Med 1993, 38, 559-568.

22. Wasiński B.: Occurrence of Leptospira serovars in pigs in the years 2002- 2003. Med Weter 2005, 61, 46-49.

23. Wolff J.W.: The laboratory diagnosis of leptospirosis. Springfield, Illinois, Charles C. Thomas, 1954, pp. 31-51.

24. Żmudzki J., Jabłoński A., Nowak A., Zębek S., Arent Z., Bocian L., Pejsak Z.: First overall report of Leptospira infections in wild boars in Poland. Acta Vet Scand. 2016, 58, 3. 